\title{
Aplikasi Tulisan Roh Nubuat Bahasa Indonesia berbasis Android
}

\author{
Application Spirit of Prophecy Writing Indonesian \\ Language based on Android
}

\author{
${ }^{1}$ Edson Yahuda Putra, ${ }^{2}$ Winona Vanya Raranta, ${ }^{3}$ Gerald Wenas \\ $1,2,{ }^{3}$ Program Studi Sistem Informasi, Universitas Klabat, Airmadidi \\ e-mail: 1eyahuda@unklab.ac.id, 211210090@student.unklab.ac.id, \\ 311023293@student.unklab.ac.id
}

\begin{abstract}
Abstrak
Roh Nubuat merupakan tulisan-tulisan yang diilhamkan Tuhan melalui Roh Kudus kepada Ellen $G$. White, dan juga merupakan buku panduan dan pegangan bagi Agama Kristen khususnya bagi Gereja Masehi Advent Hari Ketujuh (GMAHK) dalam mempelajari dan mengerti isi Alkitab dengan lebih baik. Gereja Masehi Advent Hari Ketujuh (GMAHK) percaya bahwa Tuhan berbicara Kepada Mrs. White dengan ilham ilahi dan melalui tulisan-tulisannya, Tuhan menyampaikan pekabaran yang diinspirasikan bagi gereja-Nya yang menuntun gereja itu bertumbuh dan berkembang dengan pesat dalam menyampaikan pekabaran-Nya. Serta mempersiapkan umatnya bagi kedatangan-Nya yang tidak lama lagi. Banyak buku-buku Ellen White masih ada yang belum diterjemahkan ke bahasa Indonesia, karena masih dalam bahasa Inggris. Akan lebih mudah apabila buku-buku Ellen White di terjemahkan ke dalam bahasa Indonesia agar bisa dimengerti dan dipahami. Dengan adanya teknologi yang mendukung untuk pengembangan aplikasi berbasis Android, maka pada penelitian ini, dikembangkan aplikasi berupa Tulisan Roh Nubuat versi Bahasa Indonesia berbasis Android. Tahap pengembangan penelitian ini menggunakan metode Spiral yang merupakan gabungan dari proses model Prototyping dan Waterfall. Tujuan yang dicapai dari pengembangan Aplikasi ini adalah untuk memudahkan dan menolong para pengguna untuk mengerti dan memahami isi Alkitab melalui Roh Nubuat.
\end{abstract}

Kata Kunci: Tulisan Roh Nubuat, Alkitab, Android, Spiral, Prototyping, Waterfall.

\section{Abstract}

Spirit of Prophecy is a writings that has been inspired by God through the Holy Spirit to Ellen G. White, and also was a guide book and also a handbook for Christian especially to Seventh Day Adventist Church (SDAC) for learning and understanding the Bible better. The Seventh-day Adventist Church (SDAC) believes that God speaks to Mrs. White with divine inspiration and through her writings, the Lord delivers the message inspired for His church that guides the church to grow and develop rapidly in delivering his message. As well as preparing his people for His coming soon. Many of Ellen White's books still have not been translated into Indonesian, because they are still in English. It would be easier if Ellen White's books were translated into Indonesian so that they could be understood. Since there is a technology that supports the development of Android Application, then in this study the Spirit of Prophecy Writings in Indonesian Language version with Android-based is developed. Development phase of this study using Spiral research method which is a combination of the process of the Prototyping and Waterfall models. The purpose achieved from developing this application is to simplify and help users in understanding the Bible through Spirit of Prophecy.

Key Word: Spirit of Prophecy Writings, Bible, Android, Spiral, Prototyping, Waterfall. 


\section{PENDAHULUAN}

Tulisan Roh Nubuat merupakan tulisan - tulisan yang diilhamkan Tuhan melalui Roh Kudus kepada Ellen G. White. Ny. White mengaku bahwa tulisan-tulisannya hanya sebagai terang kecil yang direncanakan Allah untuk menuntun pria dan wanita kepada terang yang lebih besar, yaitu Alkitab[1]. Tulisan-tulisan Roh Nubuat merupakan buku panduan dan pegangan khususnya bagi Gereja Masehi Advent Hari Ketujuh (GMAHK) dalam mempelajari dan mengerti isi Alkitab dengan lebih baik. Ada beberapa buku Ny. White juga berisi tentang kesehatan, pendidikan, pergaulan dan pesan bagi orang-orang muda, penatalayanan, pertarakan, sejarah, nubuatan dimasa yang akan datang, kisah hidup dari si penulis dan juga para Founder dari Gereja Masehi Advent Hari Ketujuh.

Ada berbagai jenis teknologi dikembangkan dari tahun ke tahun untuk membantu dan mempermudah manusia dalam melakukan tugas sehari-hari. Di antara beragam teknologi yang dikembangkan, smartphone adalah teknologi yang populer dan umum digunakan pada saat ini[2].

Bahasa Inggris adalah salah satu bahasa internasional yang digunakan oleh kebanyakan golongan terpelajar di seluruh dunia. Dapatdiperkirakan pula betapa beruntungnya para penutur asli bahasa Inggris. Keberuntunganitu antara lain karena untuk berbagai kepentingan internasional mercka tidak perlu belajar bahasa lain. Meskipun mereka hanya berbahasa tunggal bahasa Inggris, mereka sudah mampu menghadapi tantangan komunikasi[8].

Bahasa Inggris adalah bahasa utama dari negara Amerika Serikat yang sudah dijadikan bahasa internasional dan digunakan di negara-negara yang maju dan berkembang. Bahasa Indonesia adalah bahasa utama di negara Indonesia. Buku-buku Ellen White masih ada yang belum diterjemahkan ke bahasa Indonesia, karena masih dalam bahasa Inggris. Untuk orang Amerika Serikat, mereka mengerti isi dari buku-buku Ellen White karena bahasa dasar mereka adalah bahasa Inggris. Sedangkan untuk orang Indonesia, sulit untuk mengerti isi dari bukubuku Ellen White, karena dalam bahasa Inggris.

Akan lebih mudah apabila buku-buku Ellen White dalam bahasa Indonesia agar bisa dimengerti dan dipahami. Untuk itu dengan adanya teknologi yang mendukung untuk pengembangan aplikasi berbasis Android, penulis memanfaatkan teknologi pengembangan aplikasi Android ini untuk mengembangkan aplikasi dalam bidang kerohanian khususnya di Gereja Advent. Dalam penelitian ini penulis mengembangkan aplikasi berupa Aplikasi Tulisan Roh Nubuat versi Bahasa Indonesia berbasis Android berdasarkan aplikasi yang dibuat oleh EGW Estate yaitu EGW Writings.

EGW Writings memiliki beberapa fitur penting seperti fitur menu Utama, Daftar Buku, Pencarian, Currently Reading, Study Center, Download, Setting, Windows[3].

Melalui penelitian ini penulis berharap agar aplikasi ini dapat membantu pengguna dalam memberi kemudahan dalam membaca dan mengerti isi dari Alkitab melalui tulisan Roh Nubuat.

\section{METODE PENELITIAN}

\subsection{Model Spiral}

Dalam pengembangan Aplikasi Tulisan Roh Nubuat versi Bahasa Indonesia ini, penulis menggunakan metode Spiral sebagai model untuk mengembangkan aplikasi ini. Spiral model merupakan salah satu bentuk evolusi yg menggunakan metode iterasi natural yg dimiliki oleh model prototyping dan digabungkan dengan aspek sistimatis yg dikembangkan dengan model Waterfall[3]. Dengan menggunakan Spiral model, proses-proses dalam penelitian akan menjadi lebih cepat, namun tetap terkontrol, tersusun rapi dan teratur [8]. 


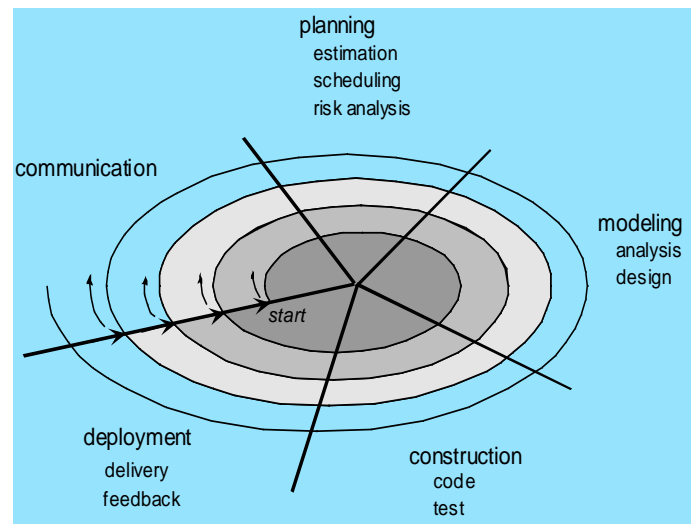

Gambar 1. Model Spiral [4]

Berikut adalah aktivitas-aktivitas yang dilakukan dalam Spiral model :

a. Communication. Aktivitas yang dibutuhkan untuk membangun komunikasi yang efektif antara developer dengan user terutama mengenai kebutuhan dari user.

b. Planning. Aktivitas perencanaan ini dibutuhkan untuk menentukan sumber daya, perkiraan waktu pengerjaan, dan informasi lainnya yang dibutuhkan untuk pengembangan software.

c. Analysis. Aktivitas analisis resiko ini dijalankan untuk menganalisis baik resiko secara teknikal maupun secara managerial. Tahap inilah yang mungkin tidak ada pada model proses yang juga menggunakan metode iterasi, tetapi hanya dilakukan pada Spiral model.

d. Construction. Aktivitas yang dibutuhkan untuk Develop Software, Testing, instalasi dan penyediaan User Support seperti Training penggunaan Software serta dokumentasi seperti buku manual penggunaan Software.

e. Deployment. Tahapan ini bisa dikatakan final dalam pembuatan sebuah Software atau sistem. Setelah melakukan analisis, desain dan pengkodean maka sistem yang telah jadi dapat digunakan oleh pengguna. Kemudian Software yang telah dibuat harus dilakukan pemeliharaan secara berkala[4]. Dan pengguna akan memberikan pendapat tentang Aplikasi yang telah dibuat. Apakah aplikasi ini akan dikembangkan kembali atau tidak.

\subsection{Kerangka Konseptual Penelitian}

Kerangka konseptual penelitian pada penelitian ini menggambarkan cara kerja sistem yang akan dibuat seperti pada Gambar 2 berikut.

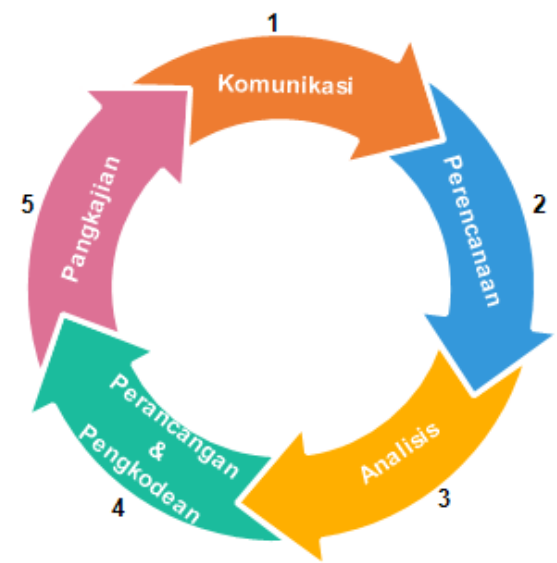

Gambar 2. Kerangka Konseptual Penelitian 
1. Komunikasi, penulis melakukan pengumpulan data dengan melakukan wawancara kepada dosen Fakultas Filsafat, teman-teman jurusan kependetaan Universitas Klabat dan studi pustaka yang terkait dengan penelitian ini.

2. Perencanaan, pada tahap ini penulis membuat jadwal kegiatan yang dilakukan selama pengembangan aplikasi ini, kemudian menyiapkan Tools yang digunakan.

3. Analisis, penulis melakukan analisis terhadap menu yang tersedia dalam aplikasi ini seperti pencarian, daftar buku-buku, bacaan sebelumnya, tentang Aplikasi dan beberapa fitur seperti fitur highlight, fitur bagikan, fitur memperbesar dan memperkecil font. Penulis juga melakukan analisis aplikasi dengan melakukan perancangan Use Case Diagram, Class Diagram, Sequence Diagram, dan Activity Diagram.

4. Perancangan, penulis melakukan perancangan antarmuka, dan database.

5. Pengkodean, penulis akan menyalin hasil rancangan ke dalam kode program dengan menggunakan bahasa pemograman yang telah ditentukan yaitu bahasa Java.

6. Pengujian, Penulis melakukan pengujian kode program dengan metode blackbox testing jika terjadi kesalahan pada program atau aplikasi.

\subsection{Kerangka Konseptual Aplikasi}

Kerangka konseptual aplikasi adalah konsep dari aplikasi yang akan dibuat oleh penulis, yang dapat dilihat pada gambar 3 berikut

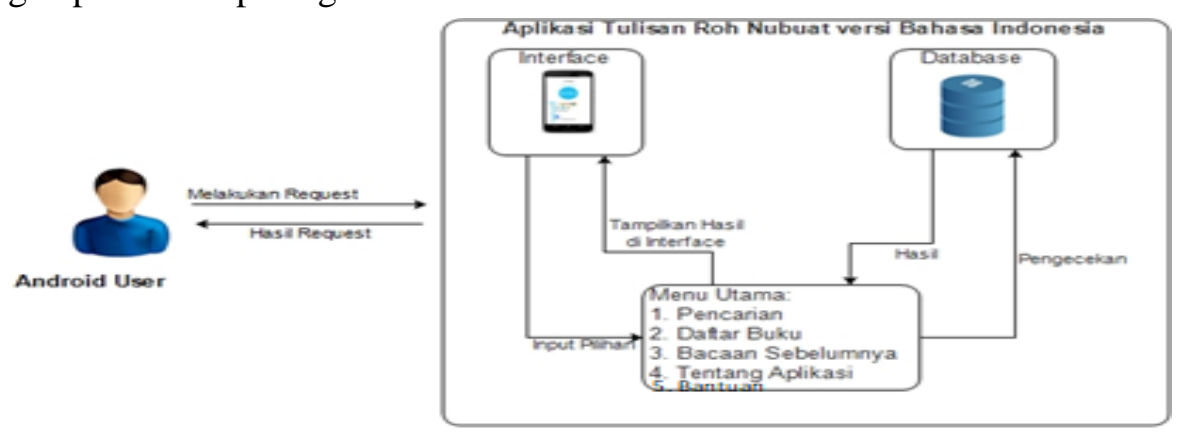

Gambar 3. Kerangka Konseptual Aplikasi

Pada gambar ini pengguna langsung berinteraksi dengan antarmuka aplikasi dan melakukan request, maka hasil request yang ditampilkan adalah pencarian berdasarkan judul buku atau kata kunci(keyword), daftar buku yang tersedia, bacaan yang telah dibaca sebelumnya. Dan aplikasi akan melakukan pengecekan di database apakah input yang diminta tersimpan dalam database Sqlite.

\subsection{Roh Nubuat}

Alkitab mengatakan bahwa ciri khusus dari umat-umat Tuhan yang sisa adalah "menuruti hukum-hukum Allah dan memiliki kesaksian Yesus" (Wahyu 12 : 17), dan "kesaksian Yesus" itu adalah "Roh Nubuat" (Wahyu 19 : 10). Kesaksian Yesus adalah Roh Nubuat. Jadi,Roh Nubuat adalh kehendak Tuhan yang dinyatakan kepada jemaat-Nya melalui saluran nubuatan atau nabi.

Ada beberapa hal yang perlu diketahui dalam pelajaran Roh Nubuat, yaitu:

a. Perlunya karunia nubuat sebagai sarana komunikasi antara Allah dan umat-Nya.

b. Informasi Alkitab mengenai ruang lingkup pekerjaan dan garis instruksi yang diberikan melalui nabi-nabi dulu kala.

c. Ciri-ciri khas manusia yang dipanggil Allah kepada pekerjaan ini dan corak masing-masing tulisan mereka. 
d. Pengalaman-pengalaman yang merupakan ciri para nabi dalam menerima dan menyampaikan pekabaran-pekabaran mereka.

e. Akibat berbagai sikap manusia dan bangsa-bangsa terhadap nabi-nabi serta pekabaran mereka.

f. Cara menerapkan pedoman Alkitabiah untuk mengetahui siapa nabi yang benar dan siapa nabi yang palsu.

g. Penggunaan karunia nubuat itu tidak berakhir pada penutupan penyusunan Alkitab (kanonisasi), melainkan masih tetap berlaku pada gereja yang sisa dan cara kerjanya pun masih tetap sama dengan pada zaman dulu.

h. Kesimpulan tentang tanggung jawab anggota-anggota gereja yang sisa dalam penggunaan karunia nubuat yang ada di tengah-tengah mereka.

i. Pengakuan Ny. E. G. White sebagai jurukabar Allah kepada gereja yang sisa.

j. Penerapan pedoman Alkitabiah pada kehidupan dan pekerjaan Ny. E. G. White sebagai nabiah (nabi perempuan).

k. Tulisan-tulisan Ny. E. G. White cocok untuk memenuhi kebutuhan orang-orang yang mempelajarinya[1].

\subsection{Android}

Android adalah sebuah sistem operasi untuk perangkat mobile berbasis linux yang mencakup sistem operasi, middleware dan aplikasi. Android menyediakan platform terbuka bagi para pengembang untuk menciptakan aplikasi mereka.

a. Lengkap (Complete Platform) : Android merupakan sistem operasi yang aman dan banyak menyediakan tools dalam membangun software dan memungkinkan untuk peluang pengembangan aplikasi.

b. Terbuka (Open Source Platform) : Pengembang dapat dengan bebas untuk mengembangkan aplikasi. Android menggunakan Linux Kernel 2.6

Free Platform : Android adalah aplikasi yang bebas untuk di-develop. Tidak ada biaya untuk dikembangkan pada platform Android, tidak diperlukan biaya pengujian, dan tidak ada kontrak yang diperlukan[5]. Android menggunakan Android SDK sebagai alat bantu dan API (Application Programming Interface) untuk mengembangkan aplikasi berbasis Android. Android SDK dapat diunduh dari situs resminya. Android SDK bersifat gratis dan bebas didistribusikan karena Android bersifat open source[6]. Tools yang digunakan adalah Eclipse. Eclipse merupakan salah satu IDE favorit karena open source. Open source berarti setiap orang boleh melihat kode pemrograman perangkat lunak ini. Selain itu, kelebihan dari Eclipse yang membuatnya populer adalah kemampuannya untuk dapat dikembangkan oleh pengguna dengan membuat komponen yang disebut plugin[7].

\section{HASIL DAN PEMBAHASAN}

\subsection{Analisis Aplikasi}

Penulis menggunakan Unified Modeling Language(UML), yaitu Use Case Diagram,

Class Diagram, Sequence Diagram, dan Activity Diagram[4]. Yang digunakan untuk memvisualisasi, merancang, dan mendokumentasikan rancangan aplikasi yang akan dikembangkan. 


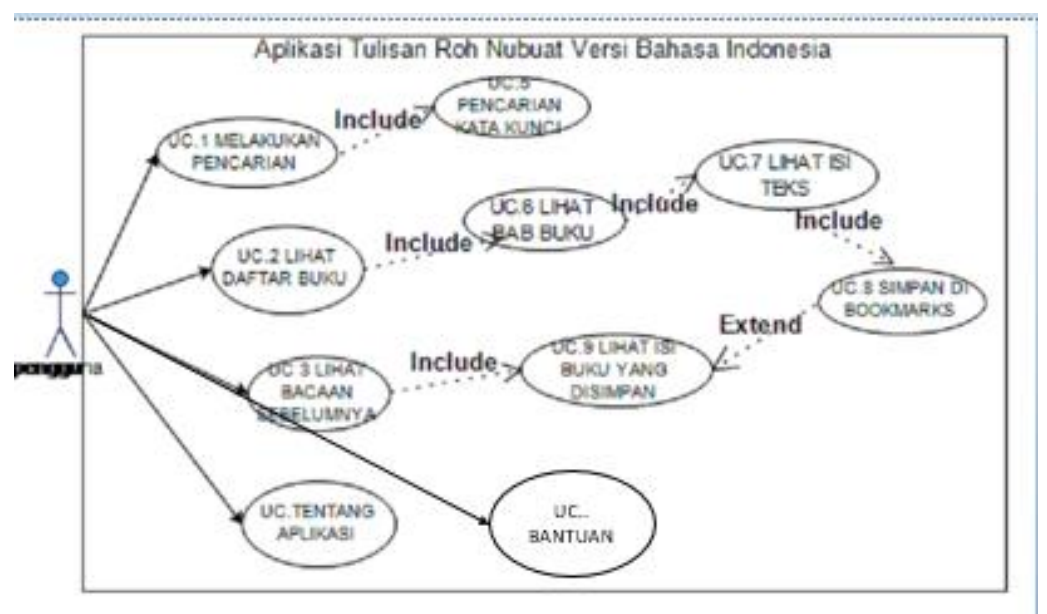

Gambar 4. Use Case Diagram

Gambar 4 menunjukkan bagaimana interaksi dan aktivitas yang terjadi antara aktor pengguna Android dengan aplikasi Tulisan Roh Nubuat versi Bahasa Indonesia. Berikut ini merupakan gambaran use case scenario berdasarkan gambar 4.

1. Use Case Name

Use Case Id

Actors

Description

Precondition

Poscondition

Steps Performed

2. Use Case Name

Use Case Id

Actors

Description

Precondition

Poscondition

Steps performed

3. Use Case Name

Use Case Id

Actors

Description

Precondition

Steps Performed
: Pencarian

$: 1$

: Pengguna Android

: Mencari buku berdasarkan kata kunci

: Pengguna mencari isi teks yang ingin dibaca

: Buku atau kata kunci ditampilkan

: 1. User memilih menu pencarian

2. Aplikasi menampilkan halaman untuk melakukan pencarian

3. Pengguna dapat mencari kata kunci

4. Aplikasi menampilkan hasil pencarian

: Daftar Buku

$: 2$

: Pengguna Android

: Melihat daftar buku yang tersedia di menu daftar buku yang ada di aplikasi

: Pengguna sudah berada di menu utama

: Daftar buku ditampilkan

: 1. Pengguna memilih menu daftar buku

2.Aplikasi menampilkan daftar semua buku Tulisan Roh Nubuat yang tersedia

: Bacaan Sebelumnya

$: 3$

: Pengguna Android

:Membaca kembali bacaan yang pernah dibaca sebelumnya

: Pengguna sudah berada pada menu utama aplikasi

:1.Pengguna memilih Menu Bacaan Sebelumnya 
4. Use Case Name

Use Case Id

Actors

Description

Precondition

Steps Performed

5. Use Case Name

Use Case Id

Actor

Description

Precondition

Postcondition

Steps Performed

6. Use Case Name

Use Case Id

Actor

Description

Precondition

Postcondition

Steps Performed

7. Use Case Name

Use Case Id

Actor

Description

Precondition

Postcondition

Steps Performed

8. Use Case Name

Use Case Id

Actor

Description
2.Aplikasi menampilkan kembali teks bacaan sebelumnya.

: Tentang Aplikasi

$: 4$

: Pengguna Android

: Melihat info Tentang Aplikasi

: Pengguna sudah berada pada menu utama aplikasi

:1.Pengguna memilih Menu Tentang Aplikasi

2.Aplikasi menampilkan info tentang aplikasi.

: Pencarian berdasarkan kata kunci

$: 5$

: Pengguna Android

: Mencari buku berdasarkan kata kunci

: Pengguna mencari isi buku yang ingin dibaca

: hasil ditampilkan

: 1. User memilih menu pencarian

2. Aplikasi menampilkan halaman untuk mengimput kata kunci

3. Pengguna dapat mencari berdasarkan kata kunci

4. Aplikasi menampilkan hasil pencarian

: Lihat bab buku

$: 6$

: Pengguna Android

: Melihat daftar bab didalam buku yang telah dipilih

: Pengguna sudah berada di daftar buku

: ditampilkan

: 1. User memilih menu pencarian

2. Aplikasi menampilkan halaman untuk mengimput judul buku

3. Pengguna dapat mencari berdasarkan judul buku

4. Aplikasi menampilkan hasil pencarian

: Lihat isi teks

$: 7$

: Pengguna Android

: Melihat teks buku yang tersedia dalam aplikasi

: Pengguna mencari buku yang ingin dibaca

: Buku ditampilkan

: 1. User memilih menu pencarian

2. Aplikasi menampilkan halaman untuk mengimput judul buku

3. Pengguna dapat mencari berdasarkan judul buku

4. Aplikasi menampilkan hasil pencarian

: Simpan di Bookmarks

$: 8$

: Pengguna Android

: simpan isi buku di bookmarks 
Precondition

Postcondition

Steps Performed

9. Use Case Name

Use Case Id

Actor

Description

Precondition

Postcondition

Steps Performed

10. Case Name

Use Case Id

Actor

Description

Precondition

Postcondition

Steps Performed
: pengguna sudah berada pada tampilan teks buku : isi buku tersimpan di bookmarks

: 1. Pengguna Menekan tombol simpan untuk menyimpan bacaan di bookmarks

2. Aplikasi menyimpan di bookmarks

: Lihat isi buku yang disimpan

$: 9$

: Pengguna Android

: lihat isi buku di bookmark

: Pengguna sudah berada di menu bacaan sebelumnya : bookmark ditampilkan

: 1. Pengguna menekan tombol bacaan sebelumnya

2. Aplikasi menampilkan bookmarks dari isi teks yang disimpan

: Lihat bantuan

: 10

: Pengguna Android

: lihat isi bantuan aplikasi

: Pengguna sudah berada di menu utama

: bantuan ditampilkan

: 1. Pengguna tombol bantuan

2. Aplikasi menampilkan bantuan aplikasi

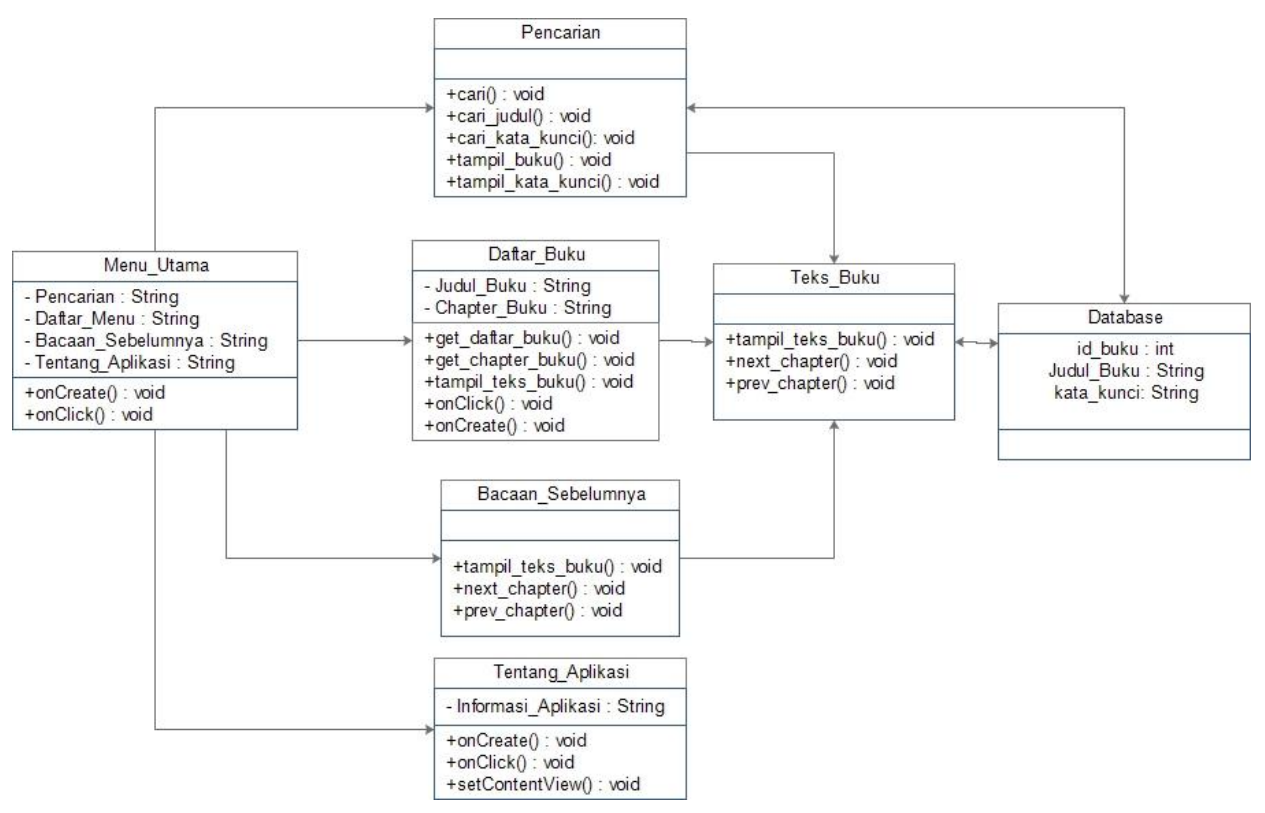

Gambar 5. Class Diagram 
Aplikasi Tulisan Roh Nubuat Bahasa Indonesia ...

\subsection{Implementasi Aplikasi}

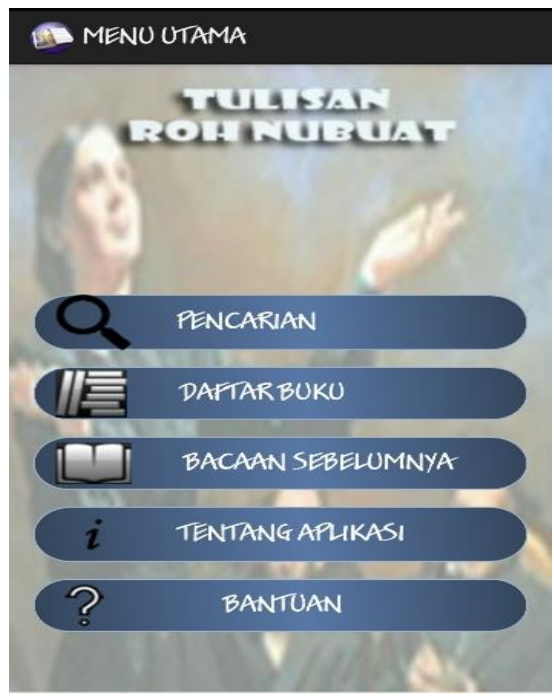

Gambar 6. Implementasi Tampilan Menu Utama

Gambar 6 merupakan tampilan menu utama untuk pengguna yang terdiri dari 5 button yang memberikan pilihan kepada pengguna diantaranya : Pencarian, Daftar Buku, Bacaan Sebelumnya, Tentang Aplikasi, Bantuan.

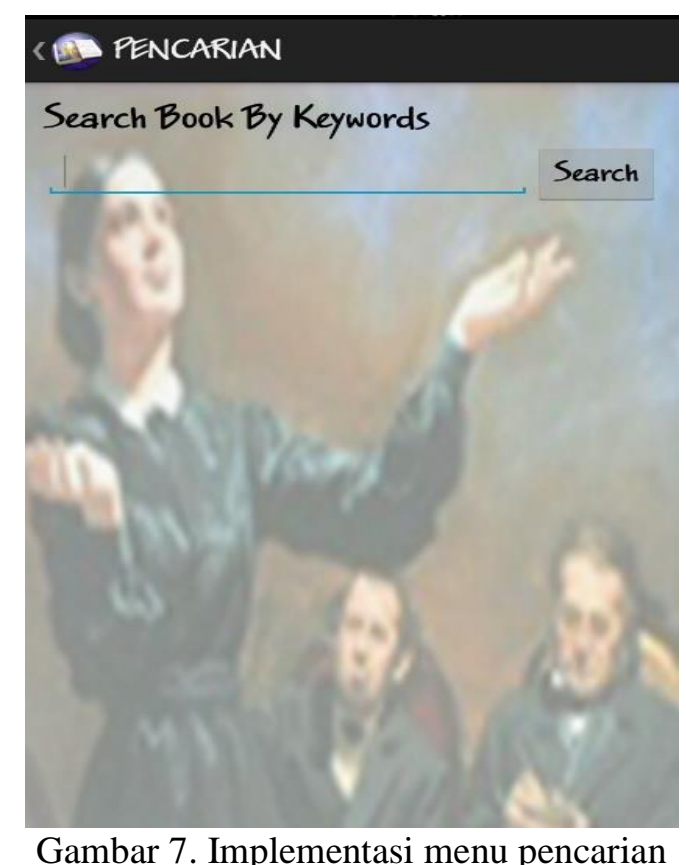

Gambar 7 merupakan tampilan dari menu pencarian dimana pengguna dapat menginput kata kunci yang akan dicari. 


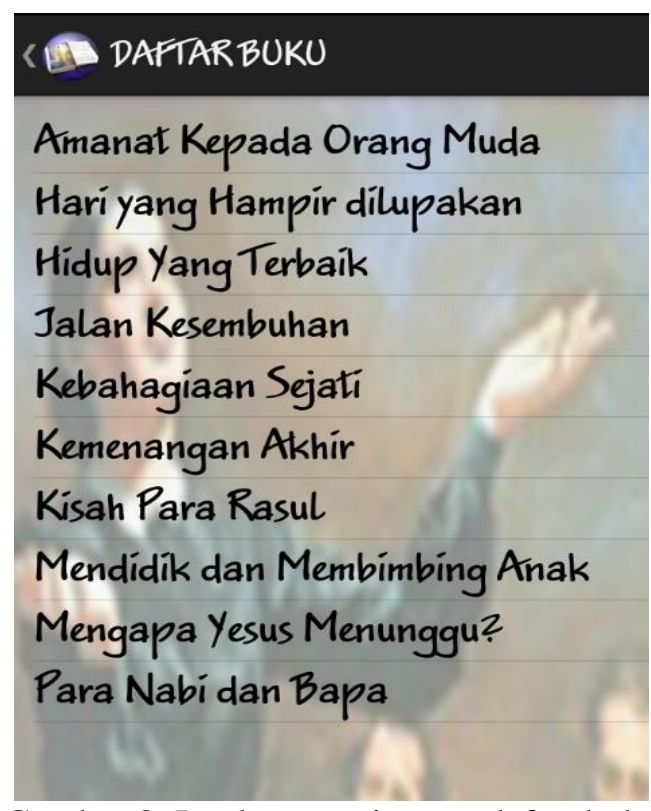

Gambar 8. Implementasi menu daftar buku

Gambar 8 merupakan tampilan daftar buku yang diurutkan berdasarkan abjad. Dari daftar ini pengguna dapat memilih satu buku yang akan dipilih.

\subsection{Tabel Pengujian Tahap Akhir}

Tabel 1. Pengujian Pencarian Kata Kunci

\begin{tabular}{|c|l|}
\hline Input & Kata kunci \\
\hline Proses & $\begin{array}{l}\text { Memasukkan input kata kunci di textfield Pencarian } \\
\text { Buku }\end{array}$ \\
\hline Output & Menampilkan kata kunci seperti yang di inputkan \\
\hline Hasil & Berhasil \\
\hline
\end{tabular}

Tabel 2. Pengujian Pencarian judul Buku di daftar Buku

\begin{tabular}{|c|l|}
\hline Input & Judul buku \\
\hline Proses & $\begin{array}{l}\text { Memasukkan input judul buku di textfield Pencarian } \\
\text { Buku }\end{array}$ \\
\hline Output & Menampilkan judul seperti yang di inputkan \\
\hline Hasil & Berhasil \\
\hline
\end{tabular}

Tabel 3. Pengujian daftar Buku

\begin{tabular}{|c|l|}
\hline Input & Daftar buku \\
\hline Proses & Menekan tombol daftar buku yang ada di menu utama \\
\hline Output & Menampilkan daftar buku \\
\hline Hasil & Berhasil \\
\hline
\end{tabular}

Tabel 4. Pengujian chapter

\begin{tabular}{|c|l|}
\hline Input & Chapter buku \\
\hline Proses & $\begin{array}{l}\text { Menekan tombol salah satu buku yang ada di daftar } \\
\text { buku }\end{array}$ \\
\hline Output & $\begin{array}{l}\text { Menampilkan daftar chapter sesuai dengan buku yang } \\
\text { dipilih di daftar buku }\end{array}$ \\
\hline
\end{tabular}


Aplikasi Tulisan Roh Nubuat Bahasa Indonesia ...

Hasil $\quad$ Berhasil

Tabel 5. Pengujian isi buku

\begin{tabular}{|c|l|}
\hline Input & Memilih chapter yang akan dibaca \\
\hline Proses & Menekan salah tombol di daftar chapter \\
\hline Output & Menampilkan isi buku \\
\hline Hasil & Berhasil \\
\hline
\end{tabular}

Tabel 6. Pengujian Bookmarks

\begin{tabular}{|l|l|}
\hline Input & Bookmark \\
\hline Proses & menekan tombol bookmark yang ada di isi buku \\
\hline Output & $\begin{array}{l}\text { Menambahkan bookmark di menu Bacaan Sebelumnya } \\
\text { dan menampilkan pesan : } \\
\text { "Halaman .. berhasil disimpan" }\end{array}$ \\
\hline Hasil & Berhasil \\
\hline
\end{tabular}

Tabel 7. Pengujian bacaan sebelumnya

\begin{tabular}{|c|l|}
\hline Input & Bookmarks \\
\hline Proses & Menekan tombol bacaan sebelumnya \\
\hline Output & $\begin{array}{l}\text { Menampilkan menampilkan daftar halaman atau isi } \\
\text { yang di bookmarks }\end{array}$ \\
\hline Hasil & Berhasil \\
\hline
\end{tabular}

Tabel 8. Pengujian Informasi Aplikasi

\begin{tabular}{|c|l|}
\hline Input & Tentang Aplikasi \\
\hline Proses & $\begin{array}{l}\text { Menekan tombol Tentang aplikasi yang ada di menu } \\
\text { utama }\end{array}$ \\
\hline Output & Menampilkan Infomasi Aplikasi \\
\hline Hasil & Berhasil \\
\hline
\end{tabular}

\section{KESIMPULAN}

Berdasarkan penelitian ini, dapat kami simpulkan bahwa:

a. Aplikasi ini dapat dioperasikan pada sistem operasi Android.

b. Aplikasi ini bisa menjadi salah satu tools untuk mempermudah para pendeta dan orangorang awan dalam membaca Tulisan Roh Nubuat.

c. Aplikasi ini juga dapat membantu para pendeta dan orang-orang awan untuk membaca dan mengerti Alkitab dengan lebih baik.

d. Aplikasi ini hanya menampung 12 buku saja, dan hanya buku - buku sudah dipublikasikan oleh IPH.

\section{SARAN}

Aplikasi ini masih dapat dikembangkan lebih lanjut dengan menambahkan buku-buku sudah dipublikasikan oleh IPH dan juga menambahkan fitur lain. Untuk kinerja aplikasi dapat dilakukan dengan pengembangan lebih lanjut agar dapat berjalan pada spesifikasi smartphone yang lebih luas. 


\section{DAFTAR PUSTAKA}

[1] R. Hutabarat, M. Div., Pengantar Roh Nubuat, Bandung, Indonesia: Indonesia Publishing House, 2000.

[2] J. Poushter, 2016, Smartphone Ownership and Internet Usage Continues to Climb in Emerging Economies, Pew Research Center, 16-20, http://assets.pewresearch.org/wpcontent/uploads/sites/2/2016/02/pew_research_ce nter_global_technology_report_final_february_22_2016.pdf

[3] E. Estate, "egwwritings," Ellen G. White Estate, 2016. [Online]. Available: https://egwwritings.org/. [Accessed 21 November 2016].

[4] Roger S. Pressman, PhD., Rekayasa Perangkat Lunak, $7^{\text {th }}$ ed., Yogyakarta, Indonesia: ANDI, 2012.

[5] N. Safaat, Pemograman Aplikasi Mobile Smartphone Dan Tablet PC Berbasis Android. Bandung: Informatika, 2012.

[6] Y. D. Lindung, "Implementasi Android SDK Dalam Pembuatan Aplikasi Mobile "Kalkulator Mipa" untuk Sekolah," in Amikom, Yokyakarta, 2012.

[7] B. Raharjo, I. Heryanto, A. Haryono, Mudah Belajar Java, Bandung: Informatika Bandung, 2010

[8] S. Lolong, E. W. Gara, R. Harimisa, 2016, Sistem Berkas Digital Untuk Berkas Penelitian di Universitas Klabat, Jurnal Cogito, vol 2, hal 264-271.

[8] M. Subiyati, 1995, Bahasa Inggris, Tumbuh, Mengglobal Dari Bahasa Tertindas Sampai Bahasa Kebutuhan Intelektual, IKIP Jogjakarta. 